\title{
A nova desordem narrativa: sujeito, tempo e discurso acentrados no romance de mulheres em Portugal
}

\author{
João Barrento \\ (Universidade Nova de Lisboa)
}

\section{RESUMO}

O artigo situa e analisa "a outra revolução" desencadeada pelo romance português entre finais das décadas de sessenta e de oitenta do século XX, com particular destaque para a ficção escrita por mulheres. Tomando como rerefência paradigmática a Obra de escritoras como Maria Velho da Costa, Teolinda Gersão e Maria Gabriela Llansol (para além de muitas outras, incluindo alguns romances no masculino), evidenciam-se os sinais da "desordem" trazida para o corpo do romance ao nível do enunciado, da temporalidade, do discurso polifónico e da hibridação genológica.

PALAVRAS-CHAVE: Romance de mulheres em Portugal; sujeito-tempodiscurso; Maria Velho da Costa; Teolinda Gersão; Maria Gabriela Llansol

\section{ABSTRACT}

The paper tries to encompass and analyse "the other portuguese revolution", the upheaval brought about in novels by portuguese women writers between the sixties and the late eighties of the 20th-century. Taking as paradigmatic reference novels by Maria Velho da Costa, Teolinda Gersão and Maria Gabriela Llansol (besides many others, including male fiction), the paper points out the main aspects of this "new narrative disorder" on the level of polyphonic discourse, temporality and hybridization of genres.

KEYWORDS: Women fiction in Portugal; subject-time-discourse; Maria Velho da Costa; Teolinda Gersão; Maria Gabriela Llansol 
Os anos setenta do século passado (e já o final da década anterior) são uma época durante a qual, no campo sociológico e político, e também no literário, se instaura uma vontade de "desordem" que põe em causa quase todas as ordens estabelecidas, da política à social, da sexual à narrativa. Por acaso, ou talvez não, datam do mesmo ano - 1977 - dois livros que, num contexto europeu em que irrompem as doutrinas feministas (com Luce Irigaray, Speculum de l'autre femme, de 1974, e Hélène Cixous/Catherine Clément, La jeune née, de 1975) e as teorias de emancipação sexual, política e discursiva (de Marcuse a Foucault e ao discurso cada vez mais subjectivado de Roland Barthes), podem constituir, no contexto português de renovação (feminina) do romance, marcos de referência para um processo global de revisão radical da própria noção de "norma" ou de "ordem" que, à distância de algumas décadas, podemos hoje fazer coincidir com a tomada de consciência de paradigmas designados de "pós-modernos", pelo menos no campo literário. Esses dois livros - de que apenas um, o português, nos interessará aqui - são $A$ Nova Desordem Amorosa, de Pascal Bruckner e Alain Finkielkraut, e Casas Pardas, o romance de Maria Velho da Costa. A estes se poderia acrescentar, por razões que não têm directamente a ver com a nova ficção de mulheres em Portugal, mas pela recusa radical do paradigma mimético e narrativo, O Livro das Comunidades, de Maria Gabriela Llansol, publicado também em 1977 (mas já pronto desde 1974). Tomo, no entanto, paradigmaticamente Casas Pardas (que Maina Mendes, de 1969, já antecipara em alguns aspectos) como referência metonímica para uma abordagem do romance português escrito por mulheres entre finais de sessenta e meados de noventa, que instaura essa nova ordem, ou desordem, na nossa narrativa contemporânea.

\section{As vozes}

A resposta à questão "Quem narra no romance?" tornou-se, há cerca de um século, num momento decisivo da modernidade literária, determinante para o futuro desta grande forma da tradição burguesa. A ruptura acontece no momento em que o leitor começa a reconhecer que a "história" - caso exista, factor que passa a ser determinante para o problema que nos interessa - não é contada a partir de fora por um narrador omnisciente e omnipotente (as mais das vezes um narrador autoral), mas que a matéria narrativa se desenvolve de forma largamente autónoma no húmus do próprio texto e se deixa ouvir a partir de uma diversidade de vozes, ou de uma voz indeterminada. E o próprio leitor, que a estética da recepção arvoraria em instância central décadas mais tarde, era, ou podia ser, uma dessas vozes.

O velho narrador, cuja voz continuará a ouvir-se até mais tarde a partir dos bastidores do romance de marca realista-naturalista mais conservadora, não deixará de se apresentar como instância com pretensões unificadoras que polariza todo o universo do romance. Mas se lermos, já em 1969, um romance como Maina Mendes ou, mais tarde, Casas Pardas, constatamos que aí domina uma polifonia discursiva e que aquela voz, a voz forte, unívoca e por vezes ditatorial do narrador que modula o discurso, se estilhaça e se desmultiplica. A vOz - que, do Génesis aos grandes sistemas filosóficos e às "grandes narrativas" modernas, foi sempre um factor hipostasiante de uma unidade e impositivo de uma ordem - cede agora a uma diversidade de vozes que não correspondem a "personagens", que não estão fixadas fora do texto, mas encontram os seus pontos de ancoragem (ou melhor, de flutuação) num discurso multiestratificado, e só aí podem ser ouvidas. Esta configuração polifónica do texto, que arrasta consigo uma fragmentação estrutural e uma 
relativização do ponto de vista face à "realidade", é exemplarmente reflectida, no próprio texto do romance, por Maria Velho da Costa:

Posso contar histórias, posso lembrar-me, a quem é que eu vou culpar neste pousio nas desordens? Eu não devia ter as imagens tão isoladamente engastadas, falta-me o percebimento do tecido, vou por brechas de luz, já disse, os ratados da malha. Mas se esbarro por ter perdido não só a sucessão do factual como a percepção do deveras maligno [...], então só me resta o que de facto ainda maravilha e a compungida ou ungida de júbilo, memória. (Velho da Costa, ${ }^{4} 1996$, pp. 141-142)

A escrita transforma-se aqui, como também em Nuno Bragança $(A$ Noite e o Riso, 1969), Almeida Faria (A Paixão, 1965, e Cortes, 1978) ou, mais tarde, em Teresa Salema (O Lugar Ausente, 1991, e Benamonte, 1997), numa orquestração de vozes, "vozes que se rebelam contra a ausência de reconhecimento do sujeito" (Lopes, 1997, p. 101). E o romance, no caso de Maria Velho da Costa, num espaço de "desordens" (desordens, aliás, rigorosamnte organizadas) em que figuras de mulher, atravessadas por uma pluralidade de vozes e atravessando os caminhos da recordação subjectiva, procuram chegar a si mesmas e à linguagem, a uma vOz a que possam chamar sua. Essa pluralidade de vozes não necessariamente identificáveis com personagens nos romances de Maria Velho da Costa (até Missa in Albis, publicado já em 1988, e que reencontramos, com marcas e com meios mais claramente pós-modernos, nos romances de Luísa Costa Gomes, O Pequeno Mundo [1988] e Olhos Verdes [1994]), que propõe uma rotura com todo o tipo de hierarquias e tem a capacidade de "maravilhar" o leitor, uma tal pluralidade parece emergir do próprio inconsciente da linguagem e vai buscar alimento às mais diversas fontes: tradições literárias ou mesmo esotéricas, diversos níveis da língua, sem hierarquias (do jargão intelectual à linguagem proletária, do balbucio infantil ao crioulo cabo-verdiano, como acontecerá até hoje, com livros como Dores, contos de 1994, e Myra, o último romance da autora, de 2008), a oralidade e a linguagem de substrato realista, o pastiche e a paródia, a citação e a hommage (em Myra, por exemplo a Amar Um Cão, de Maria Gabriela Llansol). Mas talvez o traço mais evidente da obra de Maria Velho da Costa desde Maina Mendes seja a sua capacidade única de articular a experimentação linguística, estilística e formal com a centralidade de uma problemática social e a discussão ideológica, sem cedências a qualquer forma de instrumentalização e numa linha que, em outros registos, parece ser comum a muita literatura de mulheres das últimas décadas em Portugal. Em Maina Mendes e Casas Pardas trata-se da situação marginalizada da mulher como sujeito social irrealizado, sem voz, em busca de si mesma pela via da linguagem e da escrita, ou também (sobretudo em Maina Mendes) do corpo e de um ostensivo silenciar da linguagem (um pouco à semelhança da "teologia negativa" de alguns místicos, mas sem qualquer espécie de misticismo). Em todos os casos o objectivo é o de, no "pousio das desordens", no texto e na estrutura do romance, abrir caminho a um encontro do sujeito com a sua linguagem, que é uma linguagem nova, a linguagem da utopia possível - a da mulher muda (em Maina Mendes) ou a da mulher que escreve (Elisa, em Casas Pardas), uma linguagem e uma voz que vampirizam a própria pluralidade de vozes do texto para, pela transgressão e pela via de um excesso anárquico de vozes, construir um sujeito, e assim encontrar - ou falhar - a porta de entrada na História e na sociedade. A historicidade, isto é, a ligação a um tempo concreto nestes e em outros 
romances de mulheres transparece, até hoje, no próprio "tecido", na complexa multiestratificação dos textos. A metáfora da cebola em Casas Pardas é a imagem de um microcosmo que representa simbolicamente a História/o mundo e a escrita/a linguagem. A busca de uma linguagem e de uma voz é aqui busca de um sentido. Uma busca que é tudo menos fácil: diante da cebola que tem na mão e corta ao meio, uma das três mulheres de Casas Pardas (Elvira) chega à conclusão de que "é preciso aproximar a vista, vesgar. Sofrer a perplexidade de uma indagação in extremis, próxima até doer. O juízo suspenso face à proliferação de similitudes, camadas de sentido, falas." (Velho da Costa, 1996, p. 184).

Também o facto de a pluralidade de vozes se tornar audível e gerar assim uma nova desordem narrativa (e ideológica) me parece corresponder a um importante momento de recusa e de rebelião contra o discurso dominante na ficção portuguesa - naturalmente, um discurso masculino: até ao aparecimento de figuras como Agustina Bessa-Luís e, pouco antes, Irene Lisboa, as mulheres estão praticamente ausentes do romance português do século XX. A voz do narrador tradicional era, de facto, predominantemente uma voz masculina - impositiva, linear, monótona. O que não significa que esse mesmo tom se não encontre igualmente em romances de mulheres, em particular da magna mater do romance no feminino, Agustina Bessa-Luís: "o mundo de Agustina Bessa-Luís é irrevogavelmente masculino", "o seu modelo é o mundo masculino do século XIX", escreve uma crítica e autora feminista, Fátima Maldonado, num número especial da revista suíça $D U$ sobre a literatura portuguesa (de Setembro de 1966, p. 60). O que também não afecta substancialmente o facto de escritoras tão radicalmente diferentes como Maria Velho da Costa ou Lídia Jorge (a de O Dia dos Prodígios, seu romance de estreia em 1980, ou aquela que, num encontro de 1988, afirmava que a sua geração institui uma escrita da violência, é fundadora de um "novo barroco" pela projecção da violência no discurso) testemunharem a sua dívida à primeira fase de escrita de Agustina. E também autores da (quase) última geração, como Teolinda Gersão ou Almeida Faria são, em aspectos diversos e apesar do estilhaçamento da perspectiva narrativa e da presença de uma reconhecível "questão social" na sua obra, devedores confessados de um romancista como Vergílio Ferreira: por exemplo, na visão polarizada de uma única personagem, no tratamento simbólico da existência fora das contingências da História e na obsessão da morte.

\section{Os tempos}

No seu discurso de agradecimento do Grande Prémio de Romance e Novela, atribuído ao seu romance $A$ Casa da Cabeça de Cavalo (1995), Teolina Gersão afirmava que o último e mais profundo sentido da literatura e da cultura está na memória: "na memória re-interpretada ou re-inventada pelos que vêm depois". Este será, segundo a autora, um dos aspectos-chave deste seu livro, que tomo como paradigma de uma nova forma de tratamento do tempo na ficção portuguesa. Trata-se muitas vezes de um enfoque de tempos fora do tempo histórico, particularmente presente em romances de mulheres. Antes de Teolinda, em Agustina ou Maria Judite de Carvalho, depois em Hélia Correia, Teresa Veiga, Yvette Centeno ou, com contornos muito particulares, em Maria Gabriela Llansol, em cuja Obra a dimensão histórica ganha a forma de uma comunidade trans-histórica que passa de livro para livro e se movimenta numa espécie de vazio a-temporal, num eterno presente que evoca o "instante" (nunc stans) da experiência mística de um Mestre Eckhart. A 
anulação ou amplificação do tempo, o aparecimento de formas diversas de recordação (também de formas míticas e arcaicas da memória colectiva) no lugar dos factos e das figuras históricos não se verifica, porém, exclusivamente em romances de mulheres: também David Mourão-Ferreira (nas novelas de $A s$ Quatro Estações, 1980), Urbano Tavares Rodrigues (nos contos de Fuga Imóvel, 1982), Rui Nunes ou José Riço Direitinho (nesse belo e estranho livro de contos que é $A$ Casa do Fim, 1992), subvertem a dimensão histórica em favor de uma temporalidade cíclica, simbólica, metafísica ou fantástica, e de tonalidade sempre fortemente subjectiva.

Esta manipulação do tempo, que se projecta também a outros níveis (na estrutura, nas personagens, na linguagem), é, porém, quase sempre levada a cabo por figuras femininas, muitas vezes em contextos que relevam da força associativa dos lugares (sobretudo a casa) e dos objectos, que desencadeiam as faculdades subjectivas da memória. Isabel Allegro de Magalhães fala do "poder mágico de uma acessível manipulação temporal" (Magalhães, 1995, p. 40) que explicaria a "acronia" que domina muitos romances de mulheres que se movem entre o kairós e o aion, entre o instante reanimado na memória e o sonho utópico que remete para a queda fora do tempo. O melhor exemplo para este movimento de sístole e diástole no tratamento do tempo - que torna oscilante e quase irreal o perfil histórico dos sujeitos da narrativa - é sem dúvida o de Maria Gabriela Llansol. No romance português escrito por mulheres, o tempo - sugere ainda Isabel Allegro de Magalhães - é substituído pela fuga para uma permanente viagem dos sentimentos em figuras de mulheres telúricas, solitárias e misteriosas (em Agustina, Lídia Jorge, Hélia Correia), sonhadoras em busca de uma qualquer alteridade para a existência (em Teolinda Gersão ou Teresa Veiga), mergulhadas num presente que quase sempre significa muito pouco para elas e que por isso é recoberto por momentos narrativos emocionalmente tingidos de passado ou de futuros utópicos (isto aplica-se bem às protagonistas de romances e contos de Fernanda Botelho, Maria Ondina Braga ou Maria Judite de Carvalho, quase totalmente esquecidas hoje em dia). Este trabalho de superação do tempo histórico (por vezes, como em Teolinda Gersão ou Agustina, sem prescindir de uma fixação temporal precisa, ou mesmo de datas, o que provoca um efeito de surpresa que só reforça a atmosfera atemporal dominante), este propósito de anulação da cronologia pode fazer-se sentir até ao nível da estrutura e do ritmo da linguagem, que alterna entre o fluente e o descontínuo, e que "mente" sempre que pretende organizar-se logicamente. A "acronia" pode mesmo influenciar a escolha dos tempos verbais no discurso: Teolinda Gersão utiliza o infinitivo e o condicional (em Paisagem com Mulher e Mar ao Fundo, 1992), muitas vezes o estilo nominal, em A Árvore das Palavras (1997), tal como o presente histórico, para anular o tempo ou para o alargar sem limites.

O leitor sente-se muitas vezes perdido e perplexo nestes universos da narrativa feminina, que pode ser profundamente intimista e misteriosa, fantasiosa e labiríntica. Sophia de Mello Breyner propõe-se (no conto $O$ Carrasco) contar a história de uma execução sobre a qual o leitor não chega a saber nada. Agustina Bessa-Luís constrói (em Eugénia e Silvina, 1989) uma série de hipóteses sem chegar a conclusão alguma. Yvette Centeno deixa-se guiar pelo acaso (e pelo compositor tipográfico e as suas falhas) em No Jardim das Nogueiras (1983), e confunde o leitor, até ao nível material da imagem da frase que se vai esfumando e desaparecendo na página, com as palavras sumidas e comidas; ou então, em Matriz, lança a data histórica do 25 de Abril de 1974 para uma esfera cósmica e nebulosa: "A 25 de Abril a ocultação de Vénus. Não penso no feriado que celebra a Revolução. Penso no destino, que projecto para 
as cintilações do universo." (CENTENO, 1988, p. 146) Hélia Correia cria no seu romance Insânia (1996) um entre-mundo meio mágico, meio absurdo, perpassado apenas por uma ténue vontade racional, onde as personagens vagueiam entre a permanência de forças atávicas e fenómenos inexplicáveis e um processo civilizacional descaracterizado que ameça sufocar e erradicar o velho mundo. A protagonista, Natalina, criança enjeitada e muda, torna-se no centro e no factor de perturbação de uma comunidade rural que é assaltada pela "modernidade" dos emigrantes regressados do Canadá e da televisão; outra personagem, próxima desta, o sindicalista e comunista Talívio, vê-se inexplicavelmente metamorfoseado num marceneiro e possuído das mais estranhas forças, que andam á solta pela aldeia e levam á sua morte.

Regresso a Teolinda Gersão e ao meu exemplo paradigmático para este ponto, o romance $A$ Casa da Cabeça de Cavalo. Também aqui encontramos uma rede de múltiplas vozes que emergem sem aviso prévio de um passado brumoso para entrarem num complexo jogo narrativo. Um jogo que exige do leitor a máxima atenção e o arrasta, sem que ele se dê conta, para um mundo da imaginação e da magia do tempo, dos tempos, do romance. E tudo isso é sustentado por um discurso narrativo que cultiva habilmente numa arte das transições, sem saltos, nem de capítulo para capítulo, nem adentro da mesma unidade estrutural. Mesmo as grandes emoções - aqui e em outros romances, como o percurso aventuroso de Vitória em O Cavalo de Sol (1989), as suas cavalgadas loucas e o passo em falso do adultério - são tratadas num estilo de grande serenidade, o fascínio do simbolismo e a beleza da linguagem criam um universo singular e inconfundível: um universo literário que alguns críticos viram como demasiado literarizado (ou seria antes a expressão acabada de um imaginário feminino?). Trata-se, na verdade - e aqui não andamos longe de Agustina e dos romances de outro grande autor esquecido, Augusto Abelaira de mundos do possível, de mundos do "como-se": como se a imaginação fosse diferente da realidade, e vice-versa, parecem querer dizer-nos os primeiros capítulos desse romance de Teolinda Gersão.

No universo romanesco desta autora encontram-se frequentemente uma temporalidade meândrica e figuras de mulher situadas fora do tempo. Mulheres que ocupam sempre o centro dos romances, figuras serenas ou trágicas, irradiando uma aura do passado, das origens, do autêntico, que deixa atrás de si um rasto utópico. Manifestação de uma forma de melancolia (re)activa face ao desencanto do mundo (a fórmula de Max Weber, Entz̧auberung der Welt, di-lo melhor) pequeno-burguês e novo-rico das últimas décadas, uma postura que será comum a grande parte da poesia portuguesa dos anos oitenta e noventa, como já tive oportunidade de desenvolver noutros ensaios (vd. Barrento, 1996, pp. 69-94). O arco da temporalidade neste e em outros romances transporta-nos para mundos que já não existem (por vezes até nos nomes das personagens), através de aventuras da memória e jogos de escrita que parecem demarcar-se completamente da realidade presente, e, apesar disso, ao nível daquilo a que Adorno chamou "a historicidade imanente" da arte, representam continuamente esse mesmo mundo, comentando-o a partir da memória. A matéria de que se faz uma narrativa é sempre "um resto de memória", lê-se em $A$ Casa da Cabę̧a de Cavalo (GERSÃO, 1995, p. 247). Assim, cada romance transforma-se numa espécie de testamento, cada conto num momento de revelação. 


\section{Textualização}

No ano de publicação do seu "romance" Finisterra, em 1978 - nunca antes as aspas e as reservas a propósito do termo "romance" terão sido tão ajustadas -, Carlos de Oliveira faz sair dois volumes que reunem a sua obra poética, com o título Trabalho Poético. A ênfase expressamente dada à escrita enquanto "trabalho", trabalho sobre a palavra e sobre o texto, ainda por cima num autor conotado com o neo-realismo e o marxismo, é sintomática de uma viragem já antes anunciada, a partir de outro campo estético-ideológico, por Herberto Helder (com Os Passos em Volta, de 1963). A viragem é aquela que assinala a passagem das mais diversas formas objectivantes da narrativa para formas de metaficção que mais tarde seriam plenamente recuperadas para a coutada sem cerca do pós-moderno. O que acontecia na obra de Carlos de Oliveira era o nascimento de um novo tipo de texto ficcional especular e narcísico, que a si mesmo se toma como referência e desenvolve uma gramática interna que, ao mesmo tempo, num plano simbólico, remete para uma situação de decadência social. Na mesma direcção havia já seguido Cardoso Pires em 1968, com O Delfim. Mas Carlos de Oliveira dá um passo em frente ao realizar esteticamente a superação/transformação (no sentido hegeliano de Aufhebung) da relação sujeito-objecto no texto, deixando de tratar a história como objecto, e mesmo como "moldura": aqui não existem mais objectivações, a história foi absorvida pelos próprios indícios textuais Finisterra é uma narrativa sem sujeito.

A metaficcionalidade - a reflexão do romance sobre os seus próprios meios e processos e sobre a sua matéria - é já detectável em algumas obras ficcionais anteriores a Finisterra: em alguns textos de prosa, já referidos, de Maria Velho da Costa, Nuno Bragança e Herberto Helder nos anos sessenta; ou num romance como Comente o Seguinte Texto, de Eduarda Dionísio (1972). Outros deram continuidade a este filão em anos posteriores, mas a mais coerente e radical expressão deste trabalho do texto e da quase obsessão da textualidade e da auto-referencialidade da escrita encontra-se na Obra de Maria Gabriela Llansol: aí, o romance transforma-se numa paisagem textual totalmente livre, fragmentária, labiríntica e poetizada.

O exemplo de Llansol servirá, melhor do que qualquer outro, para documentar os processos de descentramento da escrita (em relação à "realidade") e de instabilização do sujeito (nomeadamente do sujeito-leitor) desencadeados por esta "outra revolução" na narrativa portuguesa recente. Isso acontece, em primeiro lugar, pelo desaparecimento da perspectiva narrativa tradicional e pela emergência da figura do texto autocentrado (que vai ao ponto de se transformar ele mesmo em "figura"), sob a forma de uma prosa dita "obscura" ou "hermética", de grande intensidade poética, que em Llansol dá pelo nome de "fulgorização da escrita": o acto de escrita é visto por esta autora como uma espécie de flecha de luz, "porque o texto cresce quando pode enunciar, sem obstáculo, as fulgurâncias que cabem na frase, fulgurância e linguagem, uma na outra, numa só flecha." (LLANSOL, 1994b, p. 17). Em segundo lugar, assistese à mais radical negação dos géneros e das formas estabelecidos, com o resultado da total hibridação da escrita e de um uso arbitrário, mas criativo, dos códigos discursivos, sem que, no entanto, se prescinda sempre da narratividade nem da designação de "romance". Um dos testemunhos fundamentais de Llansol para a compreensão do seu próprio texto, o discurso de agradecimento do primeiro Grande Prémio de Romance, em 1991, traz o título sintomático "Para que o romance não morra": 
Os meus textos supõem um pacto de inconforto; [...] escrevo, / para que o romance não morra. / Escrevo, para que continue, / mesmo se, para tal, tiver de mudar de forma, / mesmo que se chegue a duvidar se ainda é ele, / mesmo que o faça atravessar territórios desconhecidos, / mesmo que o leve a contemplar paisagens que lhe são tão difíceis de nomear. (Llansol, 1994a, pp. 12; 116-123).

Finisterra, porém, foi e é muitas vezes visto como matriz do novo discurso ficcional, do grande "abalo textual" (Maria Alzira Seixo) no romance português. Dois dos mais evidentes "efeitos-Finisterra" - chamemos-lhe assim - em autores posteriores são, para além da já referida polifonia, a modulação uniforme da linguagem responsável pelo registo poético também na prosa, e, por outro lado (traço já dominante no romance modernista), a tendência para a reflexão, o momento ensaístico em muitos romances ou obras de prosa. Exemplos significativos desta tendência, não propriamente experimental, mas reveladora de uma forte consciência formal e linguística, são romances como Pátria Sensivel, de Casimiro de Brito (1983), Educação e Memória de André Maria S. (1982) e O Lugar Ausente (1991), de Teresa Salema, Matriz, de Yvette Centeno e textos de prosa de Nuno Júdice ou Rui Nunes. Processos frequentes são os da suspensão da narrativa, da mudança constante da perspectiva, da obsessão de uma "ideia", da solicitação do leitor para pensar ou sentir com o narrador. O próprio método da escrita torna-se visível, aberto, sem lógica de superfície, com a fragmentação a gerar totalidades simbólicas, como numa eucaristia; a totalidade emerge subitamente de uma frase aforística ou poética, propondo um sentido sempre provisório, porque a narrativa é, em princípio, infinita - em Llansol é um grande rio contínuo, d' O Livro das Comunidades (1977) a Os Cantores de Leitura (2007), um rio feito de muitos livros inclassificáveis, os éditos e agora também os inéditos, aparentemente igual mas onde nunca nos banhamos nas mesmas águas.

\section{Contaminação}

Maria Gabriela Llansol, que me serve de referência para um último momento na leitura do processo de des-subjectivação e de instabilização das instâncias narrativas desde os anos sessenta, é geralmente vista como um caso fascinante e paradoxal na literatura portuguesa contemporânea. A sua Obra será provavelmente uma das que, na prosa contemporânea, criou um dos mais amplos espectros de figuras, gerou uma das mais luminosas formas de escrita e provocou, no confronto com a "literatura" que renegava, uma das mais profundas crises dos sujeitos de produção e consumo do "romance" no nosso tempo. O seu projecto (literário, mas com forte carga filosófica) construiu-se à margem de um tempo e de uma civilização da "impostura da língua" (e da vida), e parece ter tido um objectivo essencial: escrever, de forma assistemática mas consequente, e com todos os meios disponíveis - ou seja, indiferenciadamente, com recurso a todos os géneros e formas do discurso literário, sem limites nem concessões - contra o estado do mundo, ou na "dobra" desse mundo. Escrever falando sempre de si (porque só assim se pode fugir à impostura da língua), mas sem o mínimo resquício, nem de autobiografia, nem de subjectivismo. O seu texto torna-se, assim, numa quase quadratura do círculo, é o grande paradoxo de um "poema-sem-eu" (cf. Onde Vais, Drama-poesia?, 2000, p. 13) em que a palavra passa sempre pela experiência e pelo corpo, e que se dispersa pelo "romance", o diário, o 
"conto", o fragmento, o ensaio ficcionalizado, o poema em prosa, a narrativa autobiográfica transfigurada, levando ad absurdum todo o sistema dos géneros, superando-os e neutralizando-os. É, ao mesmo tempo, um programa ascético de humildade (de "evolução para pobre") nas figuras como na linguagem, através do qual todo um conjunto de mitos e figuras centrais da nossa tradição literária e da civilização ocidental voltam a ser questionados em função da mais-valia do seu "potencial de perda".

Do ponto de vista literário, não faz sentido em Llansol a pergunta sobre a permanência ou a morte do romance, já que o espaço ficcional é aqui reduzido (ou amplificado?) à dimensão puramente textual, e tudo acontece adentro desse espaço neutro e indiferente a géneros, avesso à fixação do "sentido", mas altamente aberto às metamorfoses da significação, um espaço da total liberdade da efabulação e do trabalho com a língua. Os livros de Maria Gabriela Llansol, escrevia Maria Alzira Seixo já em 1984,

são uma das mais ricas e complexas criações ficcionais da literatura portuguesa de sempre: sem desprezar nenhum dos elementos tradicionais da narrativa, a autora produz um discurso romanesco que vale fundamentalmente pela sua organização e irradiação verbal (construindo, com Carlos de Oliveira e Maria Velho da Costa, a frase mais trabalhada e simultaneamente mais original do romance contemporâneo). (SEIXO, 1986, p. 173)

A pujança da língua não se sobrepõe, porém, nem à capacidade de criação de mundos alternativos, nem à consciência, sempre presente, de uma temporalidade-outra, histórica para lá da História. Em Llansol, mas também em outras vozes femininas da prosa portuguesa, o texto é o bastião conquistável, mas em última análise indestrutível, de uma verdade da história não importando para o caso saber se lhe chamamos História, recordação pessoal ou memória colectiva. Em alguns dos mais marcantes livros que contribuiram para essa "outra revolução" na nossa literatura recente trata-se sempre de uma estética da palavra repassada de historicidade e de temporalidade, em que a linguagem e todos os estratos da textualidade constituem o terreno e a matéria de uma inalienável consciência das forças e das contradições produtivas do presente. Uma consciência diversa e fortemente "textualizada", que traz inscritos em si os estigmas da narratividade e os vestígios da temporalidade. Por isso, a prosa portuguesa entre as décadas de sessenta e oitenta é o lugar privilegiado de um conjunto de estratégias literárias e da resistência (em última análise ideológica) do sujeito contemporâneo face às tentativas da sua neutralização pelos mecanismos de uma civilização planetária descaracterizada e incaracterística, e pela massa amorfa do pântano da chamada "pós-história" e da sua "alegre inconsciência", no qual, a cada nova anunciação do fim da História, esse sujeito ameaça afundar-se (vd., a este propósito, a reflexão mais desenvolvida em: BARRENTO, 2008, pp. 352-363). Por enquanto, a nave dos loucos continua a navegar. Nela, como escreve Llansol, estamos todos, como Édipo diante da Esfinge, "submetidos ao enigma como distinguir o jardim devastado, em que nos encontramos, do perfil da esperança." (Llansol, 1994a, p. 23). Ao colocar esta e outras questões fundamentais, Llansol responde, de forma inconfundível, com um duplo gesto: escovando a contrapêlo os textos da História $e$ do romance. 


\section{REFERÊNCIAS BIBLIOGRÁFICAS}

\section{Romances referidos (narrativa portuguesa contemporânea)}

BRAGANÇA, Nuno. A Noite e o Riso. Lisboa: D. Quixote, 1969. BRITO, Casimiro de. Pátria Sensivel. Lisboa. D. Quixote, 1983.

CENTENO, Y. K.. No Jardim das Nogueiras. Lisboa: Bertrand, 1983. Matriz: Lisboa: Presença, 1988.

DIONÍSIO, Eduarda. Comente o Seguinte Texto. Lisboa: Plátano Editora, 1972.

DIREITINHO, José Riço. A Casa do Fim. Contos. Porto: ASA, 1992.

GERSÃO, Teolinda. O Cavalo de Sol. Lisboa: D. Quixote, 1989. Paisagem com Mulher e Mar ao Fundo. Lisboa: D. Quixote, 1992. A Casa da Cabeça de Cavalo. Lisboa: D. Quixote, 1995. A Árvore das Palavras. Lisboa: D. Quixote, 1997.

GOMES, Luísa Costa. O Pequeno Mundo. Lisboa: Quetzal, 1988. Olhos Verdes. Lisboa: D. Quixote, 1994.

HELDER, Herberto. Os Passos em Volta. Lisboa: Portugália, 1963.

JORGE, Lídia. O Dia dos Prodígios. Lisboa: D. Quixote, 1980.

LLANSOL, Maria Gabriela. O Livro das Comunidades. Porto: Afrontamento, 1977.

Lisboaleipzig 1. O encontro inesperado do diverso. Lisboa: Edições Rolim, 1994a.

Lisboaleiprig 2. O ensaio de música. Lisboa: Edições Rolim, 1994b.

Onde Vais, Drama-poesia?. Lisboa: Relógio d'Água, 2000.

Os Cantores de Leitura. Lisboa: Assírio \& Alvim, 2007.

MOURÃO-FERREIRA, David. As Quatro Estações. Lisboa: Presença, 1980.

RODRIGUES, Urbano Tavares. Fuga Imóvel. Lisboa: Moraes Editores, 1982.

SALEMA, Teresa. Educaşão e Memória de André Maria S., Lisboa: D. Quixote, 1982.

O Lugar Ausente. Lisboa: D. Quixote, 1991.

Benamonte. Lisboa: Publicações Europa-América, 1997.

OLIVEIRA, Carlos de. Finisterra. Lisboa: Sá da Costa, 1978.

PIRES, José Cardoso. O Delfim. Lisboa: Moraes Editores, 1968.

VELHO DA COSTA, Maria. Maina Mendes. Lisboa: Moraes Editores, 1969. Missa in albis. Lisboa: D. Quixote, 1988.

Dores. Lisboa: D. Quixote, 1994.

Casas Pardas [1977]. $4^{a}$ edição. Lisboa: Dom Quixote, 1996. Myra. Lisboa: Assírio \& Alvim, 2008.

\section{Bibliografia citada}

BARRENTO, João. A Palavra Transversal. Lisboa: Livros Cotovia, 1996. Na Dobra do Mundo. Escritos llansolianos. Lisboa: Mariposa Azual, 2008.

LOPES, Silvina. Das Beste aus Portugal [O Melhor de Portugal]. Lisboa: Portugal-Frankfurt, 1997.

MAGALHÃES, Isabel Allegro de. O Sexo dos Textos. Lisboa: Caminho, 1995.

SEIXO, Maria Alzira. A Palavra do Romance. Lisboa: Livros Horizonte, 1986. 